\title{
Impact of the COVID-19 pandemic on a pediatric cardiovascular surgery program of a public hospital from Argentina
}

\author{
Ricardo Rodríguez, M.D. ${ }^{a}$, María Althabe, M.D. ${ }^{a}$, Mariela Krynski, M.D. ${ }^{a}$, Mercedes Montonati, M.D. ${ }^{a}$, \\ María L. Pilan, M.D. ${ }^{a}$, Belén Desocio, M.D. ${ }^{a}$, Guillermo Moreno, M.D. ${ }^{a}$, Gladys Salgado, M.D. ${ }^{b}$, \\ Javier Cornelis, M.D. ${ }^{c}$ and Miriam Lenz, M.D. ${ }^{a}$
}

\begin{abstract}
Objective. To describe the impact of the COVID-19 pandemic on a pediatric cardiovascular surgery program and estimate the necessary time to reduce the surgery waiting list.

Methods. Retrospective, descriptive study. Surgical outcomes from the pre-COVID-19 period and COVID-19 period were compared. A mathematical model was used to estimate the time necessary to reduce the waiting list.

Results. Between March $23^{\text {rd }}$ and August $31^{\text {st }}, 2020,83$ patients underwent surgery, accounting for a $60 \%$ reduction compared to the pre-COVID-19 period. Their median age was 6 months (interquartile range [IQR]: 25-75, 1.8 months to 2.9 years; $p=0.0023)$. The time necessary to eliminate the waiting list ranges from 10 to 19 months.

Conclusions. There was a $60 \%$ reduction in the program. The time required to clear the backlog of cases may range from, at least, 10 to 19 months.

Key words: COVID-19; heart surgery procedures; congenital heart disease.

http: / / dx.doi.org/10.5546/ aap.2021.eng.266
\end{abstract}

To cite: Rodríguez R, Althabe M, Krynski M, Montonati M, et al. Impact of the COVID-19 pandemic on a pediatric cardiovascular surgery program of a public hospital from Argentina. Arch Argent Pediatr 2021;119(4):266-270.

a. Department of Intensive Care (Intensive Care Unit 35).

b. Department of Cardiology.

c. Department of Cardiovascular Surgery.

Hospital de Pediatría "Prof. Dr. Juan P. Garrahan",

Autonomous City of Buenos Aires, Argentina.

E-mail address:

Ricardo Rodríguez, M.D.: ricardo.rodriguez75@gmail.com

Funding: None.

Conflict of interest: None.

Received: 9-30-2020

Accepted: 2-23-2021

\section{INTRODUCTION}

Since the onset of the COVID-19 pandemic in Wuhan, which then spread all over the world, different medical departments had to adapt their functional structure based on the needs of every country. Hospital de Pediatría Dr. Prof. Juan P. Garrahan is a tertiary care referral facility in this region, where 750 patients with congenital heart disease are operated on each year.

Argentina implemented one of the longest lockdowns, with the rescheduling of all deferrable diagnostic and therapeutic procedures. ${ }^{1}$ The high cost of waiting lists for congenital heart surgery is known $\mathrm{n}^{2,3}$ and not only affects the number of surgeries but also diagnostic and interventional procedures.

The objective of this study was to describe the impact of the COVID-19 pandemic on the cardiovascular surgery program of Hospital de Pediatría Dr. Prof. Juan P. Garrahan, and estimate the time necessary to reduce the waiting list with different scenarios of increased offer of surgical appointments and/or transient decrease in patient demand.

\section{POPULATION AND METHODS}

This was a retrospective, descriptive study. Patients who underwent surgery and recovered at the cardiovascular recovery unit of Hospital Garrahan between March 23 $3^{\text {rd }}$ and August 31 ${ }^{\text {st }}$, 2020 (COVID-19 period) were included and compared to the average of the same period in the last two years (pre-COVID-19 period). The number of surgery patients, age, complexity of the procedure according to the risk adjustment for congenital heart surgery (RACHS- 1$){ }_{,}^{4}$ place of origin, length of stay, percentage of patients on extracorporeal membrane oxygenation (ECMO), and postoperative mortality within 30 days after surgery were analyzed. The study was approved by the hospital's Associated Direction of Research and Teaching, who considered that it was not necessary to obtain consent. Results were described as median and interquartile range 
(IQR: 25-75) or absolute value and percentage, odds ratio (OR), and $95 \%$ confidence interval (95\% CI), as applicable. Comparisons were made using the $\chi^{2}$ test for discrete variables and the Wilcoxon test (U test) for continuous variables; a $p$ value $<0.05$ was considered significant. The statistical software package used was Stata $12 \AA$.

To estimate the necessary time to catch up with the waiting list resulting from the cases that were not operated during the pandemic, the equation proposed by Salenger $\mathrm{R}$ et al. was used. ${ }^{5}$

\section{Non-operated cases (NOCs) \\ (pre-COVID-19 surgeries - COVID-19 surgeries) $x$ (days of restriction $\left.{ }^{*}\right)$}

\footnotetext{
* The days of restriction are estimated as the working days since the implementation of measures until the date when full operating capacity was regained.
}

\section{Time to clear the backlog of cases (BT)}

(1 - COVID-19 surgeries/pre-COVID-19 surgeries) $x$ (days of restriction $\left.{ }^{*}\right) /\left(a^{*}-1\right)$

\footnotetext{
* The acceleration factor (a) represents the increase of appointments above the program baseline.
}

The operating capacity is 13 surgical appointments per week, except in the vacation period, when it decreases to 10 appointments.

The necessary days to catch up with NOCs were estimated, assuming that the program's usual demand will be maintained after the pandemic. Three different increase scenarios were analyzed: $15 \%, 20 \%$, and $30 \%$ with the same demand. Other three scenarios were also studied, including an estimated 15\% reduction in demand due to patients who may have lost their surgical opportunity, were operated on or may have been operated on in a different facility, and those who can delay their surgical repair for more than two years without clinical risks.

\section{RESULTS}

A total of 83 patients underwent surgery in the COVID-19 period, whereas 237 patients were operated on in the pre-COVID-19 period. This accounts for a $60 \%$ reduction in relation to the average of the previous two years in the same period (Figure 1). The median age of patients in the COVID-19 period was 6 months (IQR: 25-75, 1.8 mo-2.9 y) versus a median age of 16 months in the pre-COVID-19 period (IQR: 3 mo-6.2 y); $p=0.0023$. A total of $14 \%$ of patients underwent a highly complex surgery as measured by a RACHS score $\geq 4$. The results of the surgery were similar in both periods.

The analyzed variables and their statistical significance are described in Table 1. Due to the reduction in surgical appointments in the analyzed 102 working days, 183 patients were not operated on. Once the operating capacity increases, the necessary time to eliminate this waiting list ranges from 10 to 19 months, according to the different scenarios analyzed (Figures 2 and 3 ).

TABLE 1. Characteristics of the population comparing the pre-COVID-19 and COVID-19 periods

\begin{tabular}{|c|c|c|c|c|}
\hline & $\begin{array}{l}\text { Pre-COVID-19 period } \\
\qquad(\mathrm{N}=237)\end{array}$ & $\begin{array}{l}\text { COVID-19 period } \\
\quad(\mathrm{N}=83)\end{array}$ & $p$ value & OR $(95 \% \mathrm{CI})$ \\
\hline Surgeries with ECC & $210(88.6 \%)$ & $75(90.3 \%)$ & 0.98 & $1.01(0.70-1.46)$ \\
\hline Age (median, IQR: 25-75) & 16 mo (3 mo-6.2 y) & $6 \mathrm{mo}(1.8 \mathrm{mo}-2.9 \mathrm{y})$ & 0.0023 & NA \\
\hline \multicolumn{5}{|l|}{ Length of stay (days) } \\
\hline (median, IQR: 25-75) & $5.5(3-11)$ & $6(4-15)$ & 0.65 & NA \\
\hline Newborn infants & $28(11.8 \%)$ & $14(16.8 \%)$ & 0.40 & $1.42(0.71-2.84)$ \\
\hline Antenatal diagnosis & $14(7.9 \%)$ & $4(8 \%)$ & 0.94 & $0.81(0.26-2.54)$ \\
\hline Place of origin (AMBA) & $119(50.2 \%)$ & $48(57.8 \%)$ & 0.57 & $1.15(0.75-1.74)$ \\
\hline RACHS- 1 score $\geq 4$ & $24(10.1 \%)$ & $11(13.2 \%)$ & 0.61 & $1.30(0.61-2.78)$ \\
\hline ECMO & $6(2.5 \%)$ & $3(3.6 \%)$ & 0.90 & $1.42(0.34-5.83)$ \\
\hline PO mortality & $8 \%$ & $8.7 \%$ & 0.81 & $0.77(0.28-2.15)$ \\
\hline Heart transplants & 3 patients & 4 patients & & \\
\hline
\end{tabular}

ECC: extracorporeal circulation; IQR: interquartile range; RACHS-1: risk adjustment for congenital heart surgery; AMBA: Metropolitan Area of Buenos Aires; ECMO: extracorporeal membrane oxygenation; PO: postoperative; CI: confidence interval; OR: odds ratio. 


\section{DISCUSSION}

The heart surgery program suffered an important reduction since the onset of the pandemic. In Argentina, every year, approximately 4300 children require heart surgery in the first years of life. ${ }^{6,7}$

In order to continue with surgeries during this pandemic period, strategies to protect health care providers and patients have been implemented; among them, the creation of separate working teams and the reduction of scheduled activities to free up intensive care beds for COVID-19 patients. In spite of all the effort, the number of surgery patients decreased significantly, and the usual operating capacity will probably not recover for a couple of months. During this period, the

FIGURE 1. Number of surgery patients per month: comparison between the pre-COVID-19 (2018-2019) and the COVID-19 (2020) periods

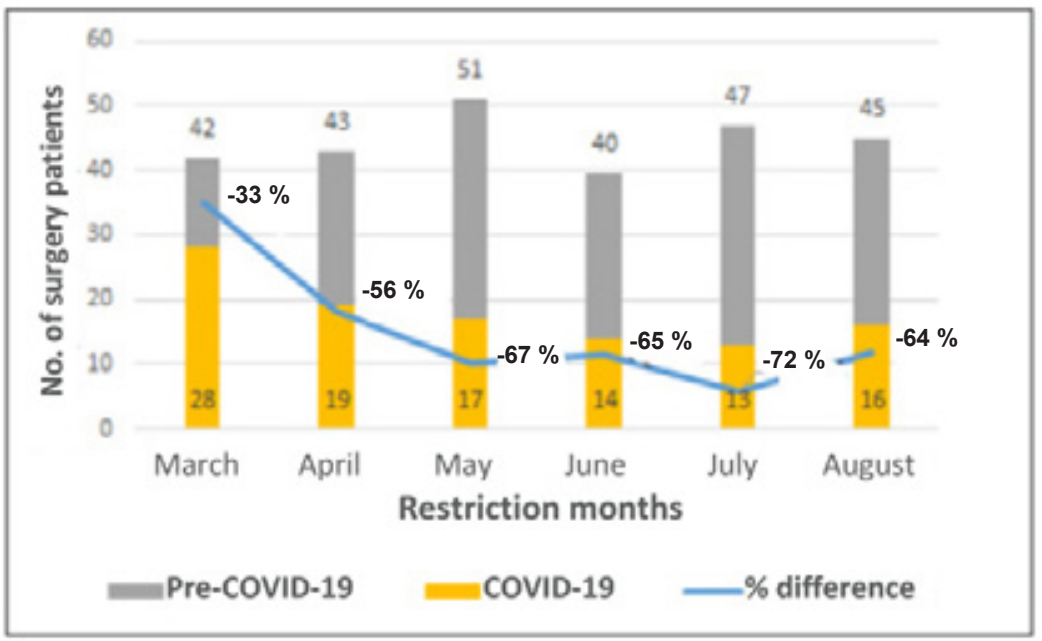

Note: The line indicates the monthly percentage decrease, the average reduction in the period is $60 \%$.

FIGURE 2. Time to clear the backlog of cases with three scenarios of increased appointment offer (15\%, 20\%, and $30 \%)$

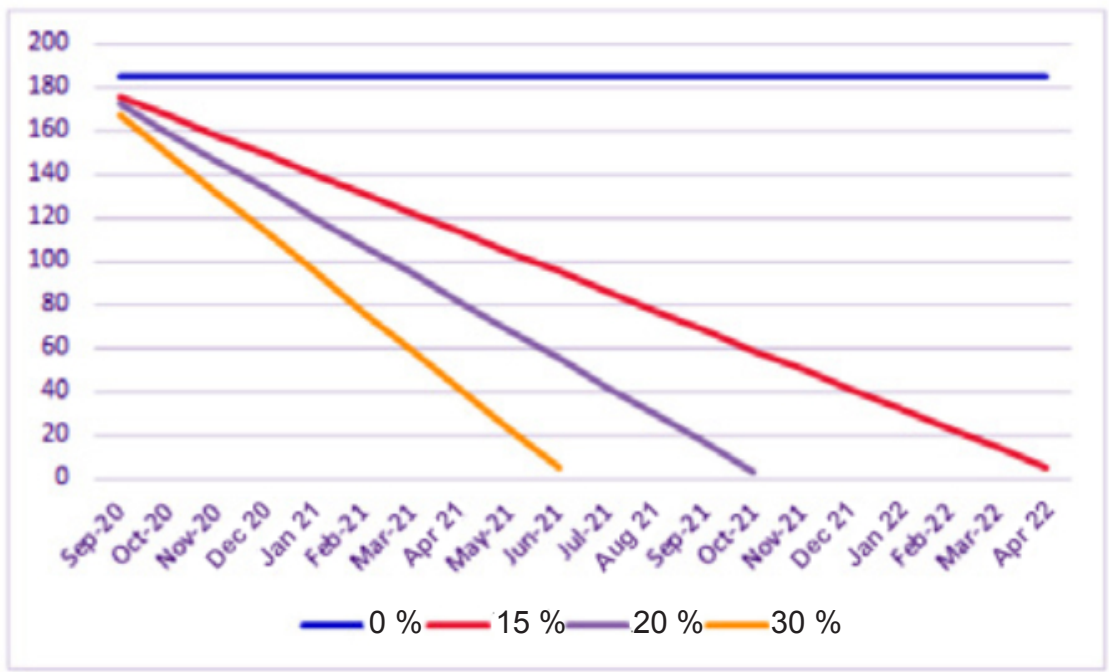

Note: The total number of non-operated cases (183) in the COVID-19 period was considered for this estimation. 
following were prioritized: a) patients with an indication for immediate surgery: newborn infants, patients with severe cyanosis, heart failure; b) patients who would be placed at a higher risk with a lack of timely resolution; ${ }^{8}$ and c) patients on the waiting list for heart transplant. All surgeries of patients whose course would not be significantly affected by surgical delay were called off. Based on these considerations, our program suffered an initial $60 \%$ reduction in the assessed period in relation to the surgery volume in the same period before the COVID-19 pandemic. These results are similar to those of other centers, as cited by Polo López et al., ${ }^{9}$ who describe a $51 \%$ reduction in major surgeries and a $54 \%$ decrease in extracorporeal surgeries. Protopapas et al., ${ }^{10}$ carried out a worldwide survey and observed that $51 \%$ of the consulted departments of cardiovascular surgery decreased their throughput by more than $50 \%$.

In our study, the days of restriction were estimated as the working days since the implementation of measures until August 31 ${ }^{\text {st }}$, 2020, when part of the operating capacity was regained.

Although it is simple to estimate the time required to catch up with non-operated patients, the implementation of strategies to minimize the impact of surgical delay on non-operated patients might be slightly more complex.
The model used to estimate the magnitude of the problem has certain limitations; however, it is a useful approximation to analyze different scenarios. The multicenter study published by Protopapas et al. states that the estimated time interval required to recover normal operations of postpandemic restrictions was 1-2 months in $43 \%$ of the programs and 2-4 months in $31 \%$. Given that our operating capacity was already stretched to the limit before the pandemic, the possibility of increasing the number of surgical appointments by more than $15-20 \%$ is very unlikely. Our model thus produces an estimate of at least 10-19 months to significantly reduce this new waiting list. Salenger et al., ${ }^{5}$ describe a $54 \%$ drop in cardiac surgical volume among adult patients; this backlog would require a monthly operating volume of $216 \%$ to $263 \%$ from baseline. Given that this would be challenging to accomplish in 1 month, they predicted that the amount of time necessary to clear the backlog would range from 1 to 8 months.

In addition to the problems of surgical appointment availability, there are other potential bottlenecks to be considered, such as the availability of intensive care beds, ward beds, and appointments for ancillary tests (e.g., catheterization, electrophysiological studies, imaging tests, etc.).

FIGURE 3. Time to clear the backlog of cases considering scenarios of increased offer and reduced demand

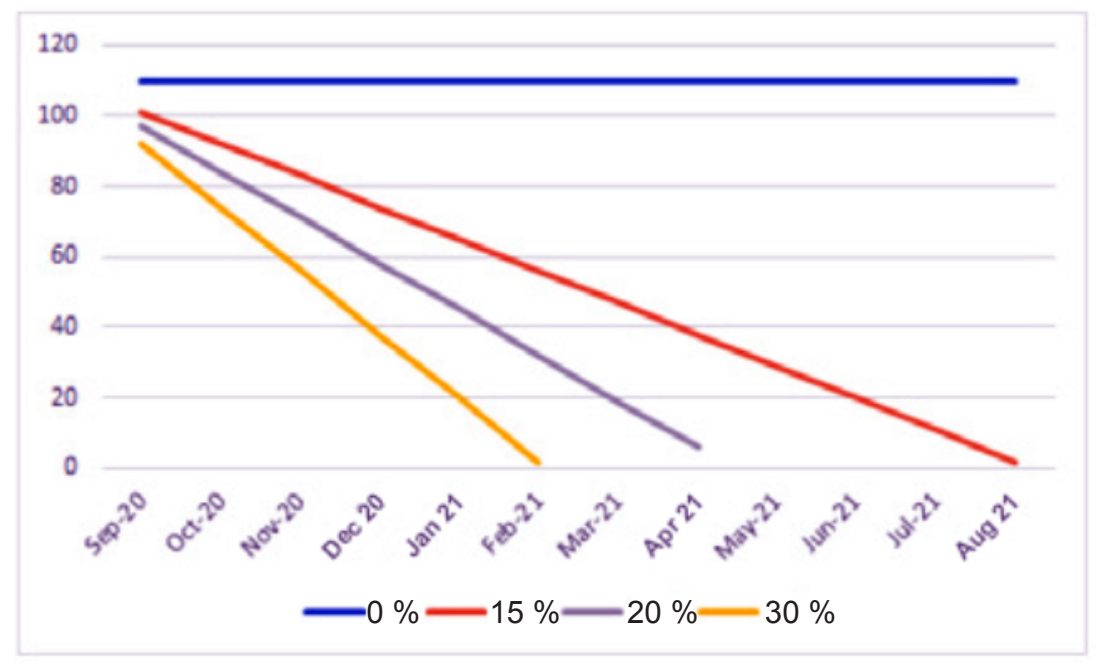

Note: In these scenarios, an estimated $15 \%$ reduction in demand due to different causes was added to the increase in appointments. 
Although the objective of this study is to show one aspect of the effects of the pandemic, extraordinary efforts will probably be required to recover activity in relation to the pre-COVID-19 era.

The limitations of this study are related to its retrospective nature and the application of a mathematical model that only provides a theoretical estimation of non-operated patients. In addition, other risks were not assessed, such as lost surgical opportunities in groups of patients at a higher risk, follow-up, and tests not performed.

\section{CONCLUSIONS}

The cardiovascular surgery program had a $60 \%$ reduction in its operating capacity between March and August compared to a similar preCOVID-19 period. The time required to clear the backlog of cases resulting from the pandemic may range from, at least, 10 to 19 months, even when implementing strategies to increase offer and postponing the resolution of patients whose condition allows surgery deferral.

\section{REFERENCES}

1. HospitalGarrahan. Licencias extraordinarias en el marco de las medidas adoptadas por el gobierno nacional. Intranet, noticias internas. 2020.
2. Althabe M, Rodríguez R, Balestrini M, Charroqui A, et al. Morbilidad en cirugía de cardiopatía congénita en un hospital público en Argentina. Arch Argent Pediatr. 2018; 116(1):e14-8.

3. Magliola R, Laura JP, Capelli H. Situación actual de los niños con cardiopatía congénita en Argentina. Arch Argent Pediatr. 2000; 98(2):130-3.

4. Jenkins KJ. Risk adjustment for congenital heart surgery: the RACHS-1 method. Semin Thorac Cardiovasc Surg Pediatr Card Surg Annu. 2004; 7(1):180-4.

5. Salenger R, Etchill EW, Ad N, Matthew T, et al The Surge after the Surge: Cardiac Surgery post-COVID-19. Ann Thorac Surg. 2020; 110(6):2020-5.

6. Villa A, Olivetti E, Capelli H. Programa Nacional de Cardiopatías Congénitas: diseño, implementación y resultados a mediano plazo. Rev Argent Salud Publica. 2015; 6(24):39-42.

7. Magliola RH, Althabe M, Moreno G, Lenz A, et al. Cardiopatías congénitas: Resultados quirúrgicos en un hospital público en Argentina. Arch Cardiol Mex. 2011; 81(3):178-82.

8. Stephens EH, Dearani JA, Guleserian KJ, Overman D, et al. COVID-19: Crisis Management in Congenital Heart Surgery. Ann Thorac Surg. 2020; 110(2):701-6.

9. Polo López L, Centella Hernández T, González Calle A, Bautista Hernández V, et al. Cirugía de cardiopatías congénitas en España durante el estado de alarma por COVID-19. Cir Cardiovasc. 2020; 27(4):137-41.

10. Protopapas E, Lo Rito M, Vida V, Sarris G, et al. Early Impact of the COVID-19 Pandemic on Congenital Heart Surgery Programs Across the World: Assessment by a Global Multi-Societal Consortium. World J Pediatr Congenit Heart Surg. 2020; 11(6):689-96.

\title{
Simulation of pediatric intubation using a low-cost videolaryngoscope in the setting of the COVID-19 pandemic
}

\author{
Daniel Rufach, M.D. ${ }^{a}$, Silvia Santos, M.D. ${ }^{b}$ and Marcelo Terebiznik, M.D. ${ }^{a}$
}

a. Hospital Interzonal de Agudos "Eva Perón”, San Martín, Province of Buenos Aires, Argentina.

b. Hospital de Pediatría "Prof. Dr. Juan P. Garrahan", Autonomous City of Buenos Aires, Argentina.

E-mail address:

Daniel Rufach, M.D.: jrufach@intramed.net

Funding: None.

Conflict of interest: None.

Received: 9-13-2020

Accepted: 2-1-2021

\begin{abstract}
In patients with SARS-CoV-2 infection, endotracheal intubation is a procedure with a high risk for transmission. A videolaryngoscopy is a supplementary level of health care provider protection, but commercial videolaryngoscopes are expensive and not always available in pediatric intensive care units in Argentina. Our objective was to describe intubation practice using an infant head mannequin with a low-cost, handcrafted videolaryngoscope.

Fifteen pediatricians with no prior experience using the device participated in an intubation practice in a head mannequin with a handcrafted videolaryngoscope. The average time for the first attempt was 116.4 seconds (95\% confidence interval [CI]: 84.8148.0) and, for the second one, 44.2 seconds (95\% CI: 27.7-60.6). Time decreased significantly for the second attempt ( $p: 0.0001)$. A successful intubation was achieved with the device in all attempts, and the procedure duration decreased with the second practice.

Keywords: videolaryngoscope, endotracheal intubation, simulation, COVID-19.
\end{abstract}

